\title{
An application of PIXE technique to Proto Crustal Rocks: Geo chemical evaluation of Granulitic Charnockites of Eastern Ghats, Andhrapradesh, India
}

\author{
A.V.S. SATYANARAYANA ${ }^{1}$, S.RAVI KUMAR ${ }^{2}$ AND S.V.R.A.N.SARMA ${ }^{3}$ \\ ${ }^{1}$ Vignan's Institute of Information Technology, Visakhapatnam, AP, India \\ ${ }^{2}$ Vignan's Institute of Information Technology, Visakhapatnam, AP, India \\ ${ }^{3}$ Vignan's Institute of Information Technology,Visakhapatnam, AP, India
}

Received: July 29, 2014 |Revised: October 06, 2015 |Accepted: December 08, 2015

Published online: February 08, 2016, The Author(s) 2016. This article is published with open access at www.chitkara.edu.in/publications

\begin{abstract}
In this work, PIXE has been used for a variety of Precambrian proto crustal rocks in the form of granulitic charnockites,Eastern Ghats AP,India. In previous study of exterior part of the charnockite hill elemental analysis using electron microprobe analysis, the elements in host charnockites no $\mathrm{Na}$, traces of $\mathrm{Mn}, \mathrm{Ca}$ and high $\mathrm{Ti}, \mathrm{Cl}, \mathrm{F}$ (Biotite), no $\mathrm{Mn}$, low $\mathrm{Na}$, and high $\mathrm{K}, \mathrm{Cl}$ (Hastingsite), and $\mathrm{Cl}, \mathrm{Fe}$ (Apatite) were only detected, but by using PIXE technique in addition to the above twenty two trace elements are identified. PIXE is highly sensitive and non-destructive method for multi elemental analysis in a variety of Precambrian charnockite rocks down to levels of a few parts per million. The samples chosen for analysis from the central portion of a charnockite hill near Visakhapatnam airport. A big reticular mass of relict litho logical body which is compositionally and physically different from host chatnockite was observed in the central portion of the hill. These experiments are carried out using a $3 \mathrm{MV}$ pelletron accelerator facility at the Institute of physics, Bhubaneswar. A collimated proton beam of $2 \mathrm{~mm}$ diameter is made to fall on to the sample, and the beam current is kept at 20na. A high resolution $\mathrm{Si}(\mathrm{Li})$ detector(160ev FWHM at 5.9kev energy) is employed in the present experiments and the Guelph PIXE (GUPIX) software package is used to analyze the spectra. The elements identified in this Precambrian charnockite rock are $\mathrm{Cl}, \mathrm{K}, \mathrm{Ca}, \mathrm{Ti}, \mathrm{V}, \mathrm{Cr}, \mathrm{Mn}, \mathrm{Fe}, \mathrm{Ni}, \mathrm{Cu}, \mathrm{Zn}, \mathrm{Se}, \mathrm{Br}, \mathrm{Rb}, \mathrm{Sr}, \mathrm{Y}, \mathrm{Zr}, \mathrm{Nb}$, $\mathrm{Mo}, \mathrm{Ru}, \mathrm{Ag}, \mathrm{Pb}$..From this study these rocks are early crust(proto crust) rocks. These samples are to belong to a very important geological phase and further work on petrography and REE (Rare Earth Elements in Geology)of the rock is indeed to firmly establish its exact parentage.
\end{abstract}

Journal of Nuclear

Physics, Material

Sciences, Radiation and Applications Vol-3, No-2

Feburary 2016 pp. $147-155$ 
Satyanarayana, AVS Keywords: PIXE Technique, Metamorphic, Precambrian, Charnockites,

Kumar, SR

Sarma, SVRAN

multi elemental analysis, Proto crustal rocks.

\section{INTRODUCTION}

As is well known the earth is conventionally divided into crust, mantle and core. The crust is further divided into three major categories continental, transitional and Oceanic. Geochemical and Petrologic investigations of Precambrian mafic[1] (metamorphic rocks containing iron and magnesium) igneous rocks play an important role in establishing the evolution of the crust. Most Precambrian exposures[2] (shields or cratons) contain metamorphic rocks and of rock were changed. The charnockite series is a group of igneous rocks[3] variably metamorphosed. They are widely distributed and occupy an important place in geology of Eastern Ghats, andhrapradesh, India, Ceylone, Madagascar and Africa. Subduction zones are the main sources for creation of continental crust. Calc-alkaline rocks typically are found above subduction zones, commonly in volcanic areas, and particularly on such area on continental crust. A widely accepted theory of the development of earth's crust states that the early earth would have had a proto crust formed from ultra mafic and felsic layers. Geologically the Visakhapatnam city, AP, India is characterized by rocks termed as Eastern Ghats. The rocks are Precambrian age and comprise mainly Khondalites, Lepitynites, Poryxene Granulites and Charnockites include Biotite, Hastingsite and Apetite minerial halogen rich compositions and all of them have undergone metamorphosis. Among these, charnockites are termed as upper mantle basic igneous rocks and are emplaced into proto crustal rocks during Precambrian times. In this way the charnockites sometimes may contain the relict bodies of earlier crustalrocks (proto crust). The proto crust is derived from primitive oceans which are also called intracratonic sea water bodies.

The samples G1 to G7 chosen for analysis are collected from the central portion of a charnockite hill [4] near Visakhapatnam airport during a demolition operation for extension of the airport. A big lenticular mass of relict lithological body(proto crustal rocks in the form of charnockite) which is compositionally and physically different from the host charnockite was observed in this central portion of the hill. This body is believed to be the caught up body of the early crustal layer (possibly proto crust).Such samples are rare, PIXE technique is chosen for the trace elemental analysis [5] of these rare samples as it is a highly sensitive and non destructive method for the simultaneous multi elemental analysis. Elements present in Ppm levels can be detected efficiently with this technique. 
Some of the trace elements are present in minute amounts in geological samples. Earlier it was very difficult to measure their precise concentrations because of non availability of sophisticated analytical methods. They were therefore described as occurring in traces, hence the term 'trace element'. With the invention of many modern analytical techniques[6] like Atomic Absorption Spectrometry(AAS) Instrumental Neutron Activation Analysis (INAA), X-Ray Fluorescence (XRF), Energy Dispersive X-Ray Fluorescence (EDXRF), Auger Electron Spectroscopy(AES), Particle Induced Gamma Ray Emission (PIGE), Particle Induced X-Ray Emission (PIXE) etc. It has become possible to estimate the concentrations of trace elements in Ppm and Ppb levels. These analytical techniques have the capability to measure all the trace elements present even in the smallest geological samples [7] with great precession and accuracy. The term trace is a traditionally followed through it has become scientifically obsolete owing to the availability improved techniques.

Among all the afore-mentioned techniques, PIXE Technique has its own advantages over the other techniques. From analytical point of view, techniques for the identification of trace elements and evaluation of their concentrations are categorized into destructive and non destructive techniques [8]. Chemical analysis and AAS are the two well known methods under the former category. Generally these methods require large amounts of sample and are tedious as they involve element-by-element analysis. PIXE and XRF are the both the methods based on X-ray emission are have several features in common. From sensitive point of view PIXE has certain superiority, moreover the bremsstrahlung produced in PIXE is a secondary effect where as in the case of electron microscope and XRF it is a primary contributor and the principal source of photon background against which the characteristic $\mathrm{x}$-rays of elemental constituents must be distinguished and hence is also the principle determinant of detection limits. The low bremsstrahlung in PIXE enables parts per million sensitivities, superior to its sister techniques. Due to high sensitivity and multi elemental analysis capability, PIXE has found applications in trace elemental analysis [9] of samples from almost every conceivable field of scientific or technical interest. Some of these fields are Biomedicine, Environment, Archaeology, Material science, Forensic studies, Industrial applications and Geology.

\section{EXPERIMENTAL DETAILS AND DATA ANALYSIS}

The experimental work was carried out previously using electron microprobe analysis, few trace elements were identified. Now using the $3 \mathrm{Mev}$ particle accelerator facility at the institute of physics, Bhubaneswar. The characteristic
An application of

PIXE technique

to Proto Crustal

Rocks: Geo

chemical evaluation

of Granulitic

Charnockites of

Eastern Ghats,

Andhrapradesh, India

\section{(n)}


Satyanarayana, AVS X-rays were detected with $\mathrm{Si}(\mathrm{Li})$ detector. The data analysis was carried Kumar, SR Sarma, SVRAN out and concentrations of various elements detected were determined using GUPIX software. Twenty two elements starting from $\mathrm{Cl}$ to $\mathrm{Pb}$ were detected in varied concentrations. On the basis of the concentrations of these different trace elements obtained using PIXE Technique, a geochemical analysis of the rock samples was performed and interpreted for the genetic significance substantiating the information from previous literature and compared with the previous study using electron microprobe analysis.

The present study is aimed at estimating the concentrations of different trace elements in geological samples of Precambrian charnockite hill near Visakhapatnam airport using particle induced X-ray emission (PIXE) technique. These experiments are carried out using $3 \mathrm{MV}$ pelletron accelerator facility at the Institute of physics, Bhubaneswar. Protons with $3 \mathrm{Mev}$ energy are used to excite the samples. The samples are mounted on an aluminium target holder (a ladder arrangement). Then the target holder is inserted into the scattering chamber and the irradiation is carried out in vacuum conditions. A collimated proton beam of $2 \mathrm{~mm}$ diameter is made to fall on to the sample. The beam current is kept at $20 \mathrm{nA}$. The samples on the target holder which are to be exited or positioned in this scattering chamber at an angle of $45^{\circ}$ with respect to the direction of the proton beam. The position of the sample relative to the beam direction is adjusted properly by viewing through a window provided in the scattering chamber. A high resolution $\mathrm{Si}(\mathrm{Li})$ detector $(160 \mathrm{eV}$ FWHM at $5.9 \mathrm{KeV}$ energy) is employed in the present experiments to record the $\mathrm{X}$ ray spectrum. The detector is placed at an angle of $90^{\circ}$ with respect to the beam direction. The output of the $\mathrm{Si}(\mathrm{Li})$ detector is coupled to data acquisition system, which records the X-ray spectrum. The spectrum of each sample is recorded for a sufficiently long time so as to ensure goods statistics. During the irradiation of each sample the charge collected and the average beam current is noted. The Guelph PIXE (GUPIX) software package is used to analyse the spectra utilizing a standard Marquardt non-linear least square fitting procedure. This package provision to identify different elements present in the sample and to estimate their relative intensities. Using this GUPIX software package the X-ray intensities of different elements are converted into the respective concentrations using a standardization technique involving fundamental parameters, pre determined instrument constants and input parameters such as solid angle, charge collected etc. Comparing the concentrations of Yttrium obtained in the present work with the known concentration of Yttrium added to the sample, the reliability of the input parameters is checked. To assure the reliability of experimental system and other parameters, in the same experimental conditions, the PIXE spectrum is recorded with NIST certified 
reference material - apple leaves 1515 (shown in table-A) and the relative concentrations of different elements are estimated. The relative concentrations of different elements thus obtained in the present experiment for the above standard samples are compared with the certified concentrations supplied by NIST. Good agreement with in experimental uncertainties is observed and this shows the reliability of the present experimental system and use of GUPIX software package in the data analysis. This technique is more efficient in the trace element analysis compared with the previous technique.

\begin{tabular}{lll}
\hline \multirow{2}{*}{ Elements } & Concentration $(\mathbf{P p m})$ & \\
\cline { 2 - 3 } & Certified values & Measured values \\
\hline $\mathrm{K}$ & $1.48 \pm 0.05$ & $1.60 \pm 0.02$ \\
$\mathrm{Ca}$ & $1.615 \pm 0.26$ & $1.53 \pm 0.02$ \\
$\mathrm{Mn}$ & $48.5 \pm 2.4$ & $54.0 \pm 3.0$ \\
$\mathrm{Fe}$ & $88.1 \pm 4.5$ & $83.0 \pm 5.0$ \\
$\mathrm{Cu}$ & $5.3 \pm 0.4$ & $5.60 \pm 0.24$ \\
$\mathrm{Zn}$ & $12.9 \pm 0.7$ & $12.5 \pm 0.03$ \\
$\mathrm{Se}$ & $0.06 \pm 0.01$ & $0.05 \pm 0.009$ \\
$\mathrm{Rb}$ & $9.3 \pm 1.0$ & $10.2 \pm 1.50$ \\
$\mathrm{~Pb}$ & $0.54 \pm 0.08$ & $0.47 \pm 0.02$ \\
\hline
\end{tabular}

Table-A
An application of PIXE technique to Proto Crustal Rocks: Geo chemical evaluation of Granulitic Charnockites of Eastern Ghats, Andhrapradesh, India

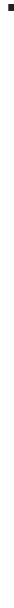

\section{RESULTS AND DISCUSSIONS}

The PIXE spectrum of the geological samples G1 to G7 collected from the interior of the charnockite rock recorded by $\mathrm{Si}(\mathrm{Li})$ detector. The concentrations in Ppm of these various elements in each sample were determined using the GUPIX software .These concentrationsare presented with errors in table-B.

Previous study of the exterior of this proto crustal rock in charnockite hill for which trace element analysis was performed using electron microprobe analysis of the trace elements $\mathrm{V}, \mathrm{Cu}, \mathrm{Rb}, \mathrm{Ag}, \mathrm{Pb}, \mathrm{Zn}, \mathrm{Zr}, \mathrm{Sr}$, Se, Mo, $\mathrm{Ru}, \mathrm{Y}$, $\mathrm{Br}$ were not detected at all while as here they are clearly observed that too in appreciable concentrations. This establishes the PIXE is the non destructive, accuracy, precision technique for the multi elemental analysis up to Ppm level and also very useful for the detection of gaseous elements like $\mathrm{Cl}, \mathrm{Br}$ in proto crustal rocks of geological samples. Chlorine, potassium, calcium, titanium, chromium, manganese, iron, zinc, bromine, rubidium, strontium, zirconium 
Satyanarayana, AVS Kumar, SR

Sarma, SVRAN

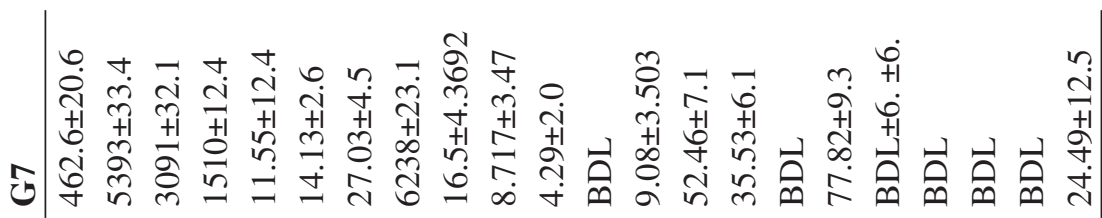

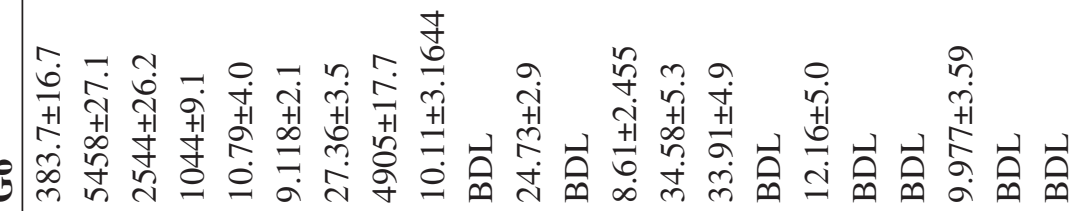

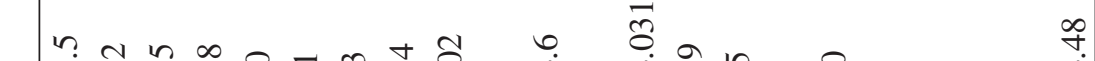

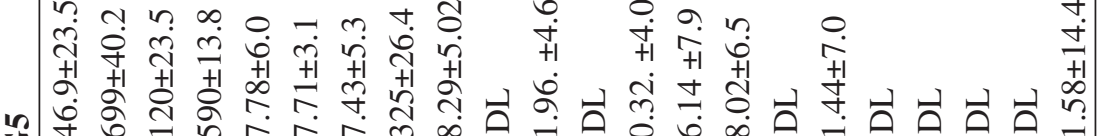

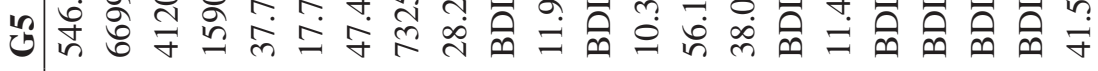

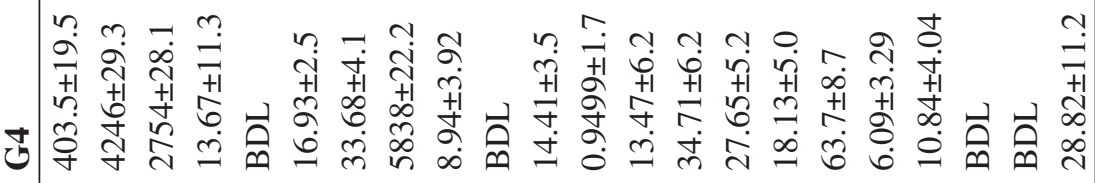

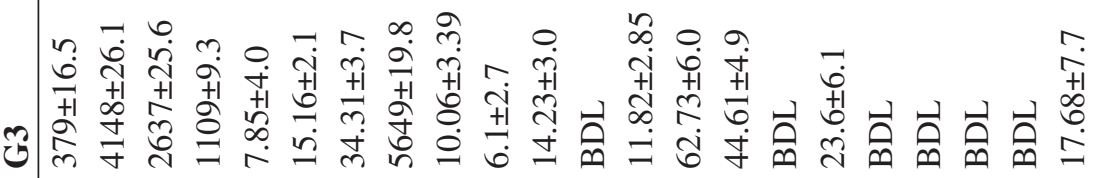

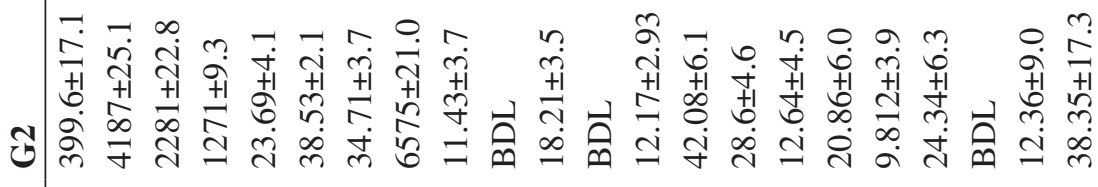

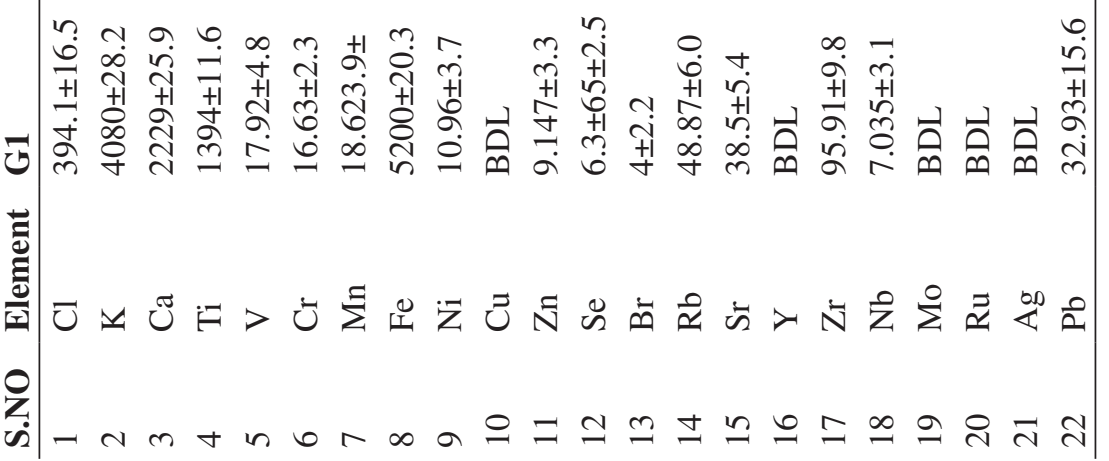


were detected all the samples, $\mathrm{Pb}$ was also detected in all the samples except in the sample G6. V was also detected in all the samples except in sample G6.

Copper was detected only in the samples G3 and G7. Similarly Se was detected in two samples G1 and G4. Y was detected in two samples G2 and G4. Nb was detected in three samples G1 and G2 and G4. Molybdenum was detected in two samples G2 and G4.Rhodium was detected in sample G6 and silver in sample G2.

It can be seen that all these samples are rich in chlorine and bromine .This anomalous chemical composition of the samples strongly supports the hypothesis that they once belonged to gaseous phase and halogen rich minerals(Biotite, Hastingsite and Apatite) because in the case of evolution of the mantle to crust many elements finding this gaseous phase. Potassium and Calcium present in high concentration $\mathrm{Rb}$ and $\mathrm{Sr}$ in appreciable quantities in all the samples supports the calcium alkaline phase. This also confirms that the previous study. Ti also present in the high concentration in all the samples has the highest concentration of all elements detected in all the samples. In addition to this high concentration of $\mathrm{Fe}$ and $\mathrm{Cr}, \mathrm{Zn}, \mathrm{Zr}$ are detected in all the samples. This strongly indicates the influence of ultramafic percentage from upper mantle. Ni present in the samples indicates that samples mantle concentration.Presence of Molybdenum in the samples G2 and G4 and that of silver in sample G2 end further support to this hypothesis. The element F was detected in the previous is very low,hence it is not appreciable quantity in eastern ghats. The major elements $\mathrm{Na}, \mathrm{Mg}, \mathrm{Al}, \mathrm{Si}$ were detected in the previous study,but here these are not detected due to low $\mathrm{Z}$ elements and detector limits and aim is trace element identification.

\section{CONCLUSIONS}

The presented PIXE technique is known for its sensitivity, accuracy, precision simplicity of thick target preparation and to perform multi elemental analysis of a large number of complex geological materials like Precambrian, proto crustal rocks compared with the previous study.This investigation clearly proved that this technique could detect not only these elemental phases but also the concentrations of gaseous elements like $\mathrm{Br}, \mathrm{Cl}$, and trace elements. The elements $\mathrm{K}, \mathrm{Ca}, \mathrm{Rb}$, $\mathrm{Sr}$ present in high concentration, low value of $\mathrm{Ni}$ in the samples supports calcium alkaline phase. The element Fe has the highest concentration, $\mathrm{Cr}, \mathrm{Zn}, \mathrm{Zr}$ are detected in the samples strongly indicates the ultramafic percentage from upper mantle. This aspect these rocks are entirely different from host charnockite and these were evolved from upper mantle to crust during Precambrian period. These rocks are early crustal
An application of

PIXE technique

to Proto Crustal

Rocks: Geo

chemical evaluation

of Granulitic

Charnockites of

Eastern Ghats,

Andhrapradesh, India




Satyanarayana, AVS

Kumar, SR

Sarma, SVRAN rocks(charnockite including Biotite,Hastingsite and Apitite) highly interesting and has partial geological applicability in similar investigations.

\section{ACKNOWLEDGMENT}

I deem it a privilege to express my deep sense of gratitude and heartiest thanks to my research director Dr.B.Seeta Rami Reddy, Associate professor, Department of Nuclear physics, Andhra University, Visakhapatnam. I am extremely indebted to Prof. M.Jagannadha Rao, Department of Geology, Andhra University, Visakhapatnam, for kindly making available the rare Geological samples and for his unstinted support and help in the geochemical evolution of the experimental data. I am thankful to Prof A.Durga Prasad Rao, Head of the Department, Department of Nuclear Physics, Andhra University, Visakhapatnam and teaching staff. I thank Dr.D.P.Mahapatro, Director, Institute of Physics, Bhubaneswar, providing accelerator facility to carry out the research work and for all amenities provided during our stay at the institute of physics.

\section{REFERENCES}

[1] A.T Rao, V.R.R.M Babu, "Allanite in charnockites rock airport hill near visakapatnam,andhrapradesh.American mineralogist:V63 (1978)330-331.

[2] B.P Radha Krishna., Forewood-precambrian mafic magmatism in the Indian shield. Jour, Geol. Soc.India,V.72(2008)5.

[3] G.Kullerud, R.M.Steffen,"Proton induced x-ray emission (PIXE): "A new tool in geochemistry"Chemical Geology:V25(1979) 245-256 http://dx.doi.org/10.1016/0009-2541(79)90145-1

[4] J.E.French, N.M.Heaaman, and R.K.Srivastava. Ma southern bastar Cuddapah mafic igneous events, India.A newly recognised large igneous province,Precambrian research.V160(2008) 308-322. http://dx.doi.org/10.1016/j.precamres.2007.08.005

[5] K.G.Malmqvist,.L.E.Bage,H.Carlesson,.K.Kristiansson, andL.Malmqvist,."New methods for mineral prospecting using PIXE and complementary techniques." Nucl Instr. and methods in physics research B: 22(1987)386-393.

[6] Luciana V,Gatti. Antonio A,Mozeto and Paulo Artaxo., Trace elements in lake sediments measured by the PIXE Technique: Nucl Instr. and methods in physics research B:150 (1999) 298-305.

http://dx.doi.org/10.1016/S0168-583X(98)01079-9

[7] R.K Srivastava, T. Ahmad, Precambrian mafic magmatism in the Indian shield, an introduction:Jour,Geol. Soc.India,V.72 (2008) 9-13. 
[8] S.H Sie,. C.G Ryan,. D.R Consens,. and W.L Griffin,: Nucl Instr. and methods in physics research B; 40/41 (1989) 690-697.

http://dx.doi.org/10.1016/0168-583X(89)91076-8

[9] S.M.Tangi,I.Orlic,X.K.Wu,.Analysis of Singapore marine sediments by PIXE: Nucl Instr. and methods in physics research B: 136-138 (1998) 1013-1017. http://dx.doi.org/10.1016/S0168-583X(97)00895-1
An application of PIXE technique to Proto Crustal

Rocks: Geo chemical evaluation of Granulitic Charnockites of Eastern Ghats, Andhrapradesh, India 